\title{
THROMBOCYTOPENIA IN MALARIA- A RETROSPECTIVE STUDY
}

\author{
Giti $\mathrm{S}^{1}$, Rahman $\mathrm{MM}^{2}$, Islam $\mathrm{MS}^{3}$, Fayezi-Bin-Saad $\mathrm{A}^{4}$, Khan $\mathrm{L}^{5}$, Bhuiyan $\mathrm{MN}^{6}$
}

\begin{abstract}
Introduction: Malaria is usually associated with low blood cell counts and mild to moderate thrombocytopenia is a common association. The cause of thrombocytopenia is poorly understood, but the immune-mediated lysis, sequestration in the spleen and diminished platelet production by the bone marrow have all been postulated.
\end{abstract}

Objectives: This study was carried out to evaluate the degree of thrombocytopenia in patients suffering from malaria.

Methods: This retrospective cross-sectional analytical study was conducted at Armed Forces Institute of Pathology (AFIP), over a period of one-year from January 2012 to December 2012. A total 81 cases of malaria parasite positive on peripheral blood film were studied by full blood counts (FBC) with automated haematology analyzer Sysmex 1800i. Thick and thin smears were stained with Giemsa and Leishman stains and examined by haematologist. Data was analyzed using the SPSS version 10.0.

Results: Out of 81 patients, all were male. Mean age was 24.3 years (Mean+2SD:24.3 \pm 10.7 ) with a range of 23-42 years. Plasmodium falciparum was detected in $61(75.3 \%)$ cases, P. vivax in $16(19.8 \%)$ and mixed infection in $04(4.9 \%)$ cases. Haemoglobin values in patients of malaria with thrombocytopenia and without thrombocytopenia were $10.8 \pm 3.2 \mathrm{~g} / \mathrm{dl}$ and $12.2 \pm 2.6 \mathrm{~g} / \mathrm{dl}$ respectively. White blood cell counts in patients with and without thrombocytopenia were $6.2 \pm 4.3 \times 10^{9} / \mathrm{L}$ and $9.3 \pm 5.2 \times 10^{9} / \mathrm{L}$ respectively.
Out of 81 patients, $23(28.4 \%)$ had normal platelet counts, and $58(71.6 \%)$ had thrombocytopenia. Platelet counts in patients with malaria with and without thrombocytopenia were $48.1 \pm 25.3 \times 10^{9} / \mathrm{L}$ and $199 \pm 45.4 \times 10^{9}$ respectively. The mild, moderate and severe thrombocytopenia were found in 44 (75.9\%), 09 (15.5\%) and 05 (8.6\%) cases respectively. Platelet counts of $<20 \times 10^{\circ} / \mathrm{L}$ were noted in only $8.6 \%$ cases of falciparum malaria and none in vivax malaria.

Conclusion: The study found high frequency of mild to moderate thrombocytopenia in the Plasmodium falciparum and plasmodium vivax malaria. Although thrombocytopenia is uncommon in malaria, its presence is not a distinguishing feature between the two types. Finding of thrombocytopenia in a patient with fever is of diagnostic help as it raises the suspicion of malaria. Thrombocytopenia of $<20 \times 10 \%$ can occur in $P$. vivax malaria although it is statistically more common with $P$. falciparum malaria. The above findings can have therapeutic implications in context of avoiding unnecessary platelet infusions with the relatively benign course in $P$. vivax malaria.

Key-words: Thrombocytopenia, Malaria, Plasmodium falciparum, Plasmodium vivax.

\section{Introduction}

The estimated annual global incidence of malaria is 300-500 million cases and about 20 million deaths occur worldwide each year ${ }^{1}$. Bangladesh is one of the 109 countries listed by the World Health Organization as having endemic malaria.

1. Brig Gen Susane Giti, MBBS, MCPS, FCPS, Classified Specialist in Pathology, AFIP, Dhaka; 2. Col Md Mizanur Rahman, MBBS, MCPS, DCP, FCPS, Classified Specialist in Pathology, AFIP, Dhaka; 3. Maj Gen Md Saiful Islam, MBBS, MCPS, FCPS, Ex-Commandant and Classified Specialist in Pathology, AFIP, Dhaka 4. Dr Ahmed Fayezi-Bin-Saad, MBBS, Resident Medical Officer, Dhaka Medical College, Dhaka; 5. Maj Lutfunnahar Khan, MBBS, MCPS, DCP, FCPS, Graded Specialist in Pathology, CMH Jessore; 6. Maj Mohammed Nuruzzaman Bhuiyan, MBBS, MCPS, DCP, Graded Specialist in Pathology, AFMI, Dhaka. 
Within Bangladesh, 13 of the 64 districts are considered to have endemic malaria, with 26.9 million people living in these 13 districts, a population larger than many African countries, which illustrates the scope of the risk from malaria $^{2}$. A cross-sectional survey for malaria infection was conducted in 2007 by International Centre for Diarrhoeal Disease Research, Bangladesh (ICDDRB) with Bangladesh Rural Advancement Committee (BRAC) to establish a baseline estimate of malaria prevalence in the population living in the 13 malaria endemic districts. This cross-sectional survey showed a malaria prevalence of $13 \%$ by Rapid Diagnostic Test (RDT) in the Chittagong Hill Tracts (15.5, 10.7 and 6.8 percent in Khagrachari, Bandarban and Rangamati districts respectively) with the overall prevalence of 45 per thousand population of fever associated with malaria in these three hill districts. About $89 \%$ of the infections were caused by Plasmodium falciparum, $5 \%$ by Plasmodium vivax and the remaining $6 \%$ by mixed infection. Asymptomatic prevalence in five southeastern districts was $40 / 1,000$ versus $2 / 1,000$ population in the eight northeastern districts. Such high rates of asymptomatic malaria infection suggested a need for further surveillance and control measures ${ }^{2}$.

Various degrees of low blood counts, and mild to moderate thrombocytopenia is a common association of malaria but its is rarely associated with haemorrhagic manifestations or a component of Disseminated Intravascular Coagulation (DIC) ${ }^{3}$. The cause of thrombocytopenia is poorly understood, but the immune-mediated lysis, sequestration in the spleen and a dyspoietic process in the marrow with diminished platelet production have all been postulated. Abnormalities in platelet structure and function have been described as a consequence of malaria, and in rare instances, platelets can be invaded by malarial parasites themselves ${ }^{4}$. Tumour Necrosis Factor (TNF) and 'IL-10' have been implicated in the development of Plasmodium falciparum malaria induced anaemia, but the role of these cytokines has not been studied in the development of thrombocytopenia in patients with acute malaria ${ }^{5}$. The aim of this study was to find out the pattern of thrombocytopenia in patients suffering from acute malaria and it also attempted to correlate the low platelet count with the type of malaria.

\section{Materials \& Methods}

This retrospective cross-sectional analytical study was conducted in AFIP, Dhaka Cantonment over a period of one year from January 2012 to December 2012. A total of 81 malaria patients, positive on peripheral blood film, were included in the present study. Full blood counts were determined by using automated haematology analyzer, Sysmex 1800i. Thick and thin smears were stained with Giemsa and Leishman stains and were studied by haematologist. Those with reduced platelet count were re-evaluated by manual method. Patients with thrombocytopenia were divided in three categories. Platelet (PLT) count of $<150 \times 10^{9} / \mathrm{L}$ but more than $>50 \times 10^{9} / \mathrm{L}$ was labelled as mild thrombocytopenia, moderate thrombocytopenia as the PLT count of $<50 \times 10^{9} / \mathrm{L}$ but more than $\geq 20 \times 10^{9} / \mathrm{L}$ and severe thrombocytopenia as PLT count of $<20 \times 10^{9} / \mathrm{L}$. Patients with history of bleeding disorder, cerebral malaria, acute renal failure and drug intake such as Quinine, Sulfadoxine-Pyrimethamin, Thiazides, Co-trimoxazole, and other haemolytic agents were excluded from the study. Data was entered on Microsoft excel spreadsheet and statistical analysis was performed with SPSS Version 10.0.

\section{Results}

Out of 81 patients, all were male. Mean age was $24.3 \pm 10.7$ years. Table-I shows the demographic data of the patients. A different type of plasmodium species found in this study is shown in Table-II. Baseline haematological parameters of patients with and without thrombocytopenia were shown in Table-III and Table-IV. Haemoglobin values in patients of malaria with thrombocytopenia and without thrombocytopenia were $10.8 \pm 3.2 \mathrm{~g} / \mathrm{dl}$ and $12.2 \pm 2.6 \mathrm{~g} / \mathrm{dl}$ respectively. White blood cell counts in patients with and without thrombocytopenia were found to be $6.2 \pm 4.3 \times 10^{\%} / \mathrm{L}$ and $9.3 \pm 5.2 \times 10^{9} / \mathrm{L}$ respectively. Out of 81 patients, $23(28.4 \%)$ had normal platelet count and $58(71.6 \%)$ had thrombocytopenia as shown in Table-V. Table-VI shows the distribution of patients on the basis of thrombocytopenia and plasmodium species. The mild, moderate and severe thrombocytopenia were found in 45 (75.9\%), 09 (15.5\%) and 04(8.6\%) cases respectively as shown in Table-VII. 
Table-I: Demographic data of patients with malaria $(n=81)$.

\begin{tabular}{|l|l|}
\hline Age Range $(\mathrm{yrs})$ & $23-42$ \\
\hline Mean & 24.3 \\
\hline Mean \pm 2 SD & $24.3 \pm 10.7$ \\
\hline Sex & 81 \\
\hline Male & 00 \\
\hline Female &
\end{tabular}

Table-II: Distribution of Plasmodium Species $(\mathrm{n}=81)$.

\begin{tabular}{|l|c|c|}
\hline Plasmodium species & Number & $(\%)$ \\
\hline P. falciparum & 61 & 75.3 \\
\hline P. Vivax & 16 & 19.8 \\
\hline Mixed (P. falciparum + P. vivax) & 04 & 4.9 \\
\hline
\end{tabular}

Table-III: Base line haematological parameters of patients with thrombocytopenia $(n=81)$.

\begin{tabular}{|l|c|c|c|}
\hline Parameters & Range & Mean & Mean \pm 2SD \\
\hline $\mathrm{Hb}(\mathrm{g} / \mathrm{dl})$ & $8.0-14.0$ & 10.8 & $10.8 \pm 3.2$ \\
\hline $\mathrm{TLC}\left(\mathrm{X} 10^{9} / \mathrm{L}\right)$ & $3.7-11.5$ & 6.2 & $6.2 \pm 4.3$ \\
\hline Platelet $\left(\mathrm{X} 10^{9} / \mathrm{L}\right)$ & $20-140$ & 48.1 & $48.1 \pm 25.3$ \\
\hline
\end{tabular}

Table-IV: Base line haematological parameters of patients without thrombocytopenia $(n=81)$.

\begin{tabular}{|l|c|c|c|}
\hline Parameters & Range & Mean & Mean \pm 2SD \\
\hline $\mathrm{Hb}(\mathrm{g} / \mathrm{dl})$ & $8.0-14.0$ & 12.2 & $12.2 \pm 2.6$ \\
\hline $\mathrm{TLC}\left(\mathrm{X} 10^{9} / \mathrm{L}\right)$ & $3.7-11.5$ & 9.3 & $9.3 \pm 5.2$ \\
\hline Platelet $\left(\mathrm{X} \mathrm{10^{9 } / \mathrm { L } )}\right.$ & $168-240$ & 199.0 & $199.0 \pm 45.4$ \\
\hline
\end{tabular}

Table-V: Distribution of patients presenting with and without thrombocytopenia $(n=81)$.

\begin{tabular}{|l|c|c|}
\hline Variables & Number & $\mathbf{( \% )}$ \\
\hline With thrombocytopenia & 58 & 71.6 \\
\hline Without thrombocytopenia & 23 & 28.4 \\
\hline
\end{tabular}

Table-VI: Distribution of patients on the basis of thrombocytopenia and plasmodium species $(n=81)$.

\begin{tabular}{|l|c|c|c|}
\hline $\begin{array}{l}\text { Plasmodium } \\
\text { Species }\end{array}$ & Number & Thrombocytopenia & $\begin{array}{c}\text { Without } \\
\text { thrombocytopenia }\end{array}$ \\
\hline P. falciparum & $61(75.3 \%)$ & $45(73.8 \%)$ & $16(26.2 \%)$ \\
\hline P. vivax & $16(19.8 \%)$ & $09(56.3 \%)$ & $07(43.7 \%)$ \\
\hline Mixed & $04(4.9 \%)$ & $04(100 \%)$ & $00(00 \%)$ \\
\hline
\end{tabular}

Table-VII: Severity of thrombocytopenia among the thrombocytopenic patients $(n=58)$.

\begin{tabular}{|l|c|c|c|}
\hline Variables & Plasmodium Species & Number & $(\%)$ \\
\hline Mild $\left(<150->50 \times 10^{9} / L\right)$ & $\begin{array}{c}\text { P.falciparum + P.vivax } \\
+ \text { Mixed infection }\end{array}$ & $\begin{array}{c}32+08 \\
+04\end{array}$ & 75.9 \\
\hline Moderate $\left(<50->20 \times 10^{9} / L\right)$ & P. falciparum + P. vivax & $08+01$ & 15.5 \\
\hline Severe $\left(<20 \times 0^{9} / L\right)$ & P. falciparum & 05 & 8.6 \\
\hline
\end{tabular}

\section{Discussion}

In malaria haematological abnormalities are commonly observed. Thrombocytopenia often accompanies malaria and is usually mild to moderate in severity but very rarely symptomatic. Thrombocytopenia occurs in $60-80 \%{ }^{6}$ and anaemia in $25 \%{ }^{7}$ of patients with malaria. Finding of thrombocytopenia with anaemia is an important clue to the diagnosis of malaria in patients with acute febrile illness ${ }^{8}$. In this study, $71.6 \%$ of patients suffering from malaria showed some degree of thrombocytopenia. This figure is comparable to studies done by other investigators as $69.5 \%$ by Ansari $^{9}, 71 \%$ by Robinson ${ }^{10}, 58.97 \%$ by Rodringuez et $\mathrm{al}^{11}$ and $51.92 \%$ by Mosleh Uddin $^{12}$. Thrombocytopenia is considered to be an important predictor of severity in childhood falciparum malaria ${ }^{13}$.

Bashwari et al $^{14}$ from Saudi Arabia has reported anaemia in $60 \%$ and thrombocytopenia in $53 \%$ of cases. Thrombocytopenia is seen in patients with acute febrile illness due to viral causes as well but its presence is considered to be an important diagnostic clue for malaria in endemic areas as suggested by previous investigators ${ }^{8}$ and particularly so when associated with anaemia ${ }^{15}$. In Liberia Mahmood et $\mathrm{al}^{16}$ studied a total of 145 patients who had Plasmodium falciparum malaria, out of these 109 (75.18\%) had thrombocytopenia. The sensitivity of the platelet count, considered as a predictor of malaria, was $80.11 \%$ while specificity was $81.36 \%$. The positive predictive value was $63.87 \%$ and the negative predictive value was $90.86 \%$.

Study by Mamood et al included an extended search for malarial parasites in patients having thrombocytopenia on smear ${ }^{16}$. Mild to severe thrombocytopenia should predict the possibility of malarial infection, as Plasmodium falciparum was found to be common species in these patients ${ }^{17}$. It is a general consensus that thrombocytopenia is very common in malaria ${ }^{18}$ and this is usually believed to be more common in Plasmodium falciparum malaria, as has been observed in this study. Maximum thrombocytopenia occurred on the fifth or sixth day of infection, and gradually returned to normal within 5-7 days after parasitaemia ceased ${ }^{19}$. 


\section{Conclusion}

We found high frequency of mild to moderate thrombocytopenia in the Plasmodium falciparum and plasmodium vivax malaria. Although absence of thrombocytopenia is uncommon in malaria, its presence is not a distinguishing feature between the two types. Finding of thrombocytopenia is of diagnostic help as it raises the suspicion of malaria. Thrombocytopenia of $<20 \times 10^{9} / \mathrm{L}$ can occur in $P$. vivax malaria although statistically more common with $P$. falciparum malaria. The above findings can have therapeutic implications in context of avoiding unnecessary platelet infusions with the relatively benign course in $P$. vivax malaria. Patients with acute febrile illness having combination of thrombocytopenia and anaemia should alert the treating physician about the possibility of malaria infection which can be confirmed with specific tests.

\section{References}

1. Khan MA, Smego RA Jr, Razi ST, Beg MA. Emerging drug resistance and guidelines for treatment of malaria. Med Today 2006; 4:81-7.

2. Wasif AK, David AS, Sabeena A. Mapping hypoendemic, seasonal malaria in rural Banderban, Bangladesh: a prospective surveillance. Malaria Journal 2011; 10:124.

3. Ladhani S, Lowe B, Cole AO, Kowuondo K, Newton CR. Changes in white blood cells and platelets in children with falciparum malaria: Relationship to disease outcome. $\mathrm{Br} \mathrm{J}$ Haematol 2002; 119:839-47.

4. Jadhav UM, Patkar VS, Kadam NN. Thrombocytopenia in malaria - correlation with type and severity of malaria. J Assoc Physicians India 2004; 52:615-8.

5. Tacchini CF, Vesin C, Redard M, Buurman W, Piguet PF. Role of TNFR1 and TNFR2 in TNF-induced platelet consumption in mice. J Immunol, 1998; 160:6182-6.

6. Kreil A, Wenisch C, Brittenham G. Thrombocytopenia in $\mathrm{P}$ falciparum malaria. $\mathrm{Br} \mathrm{J}$ Hematol 2000; 109:534-6.
7. Kathryn NS, Kevin C, Jay SK. Malaria. CMAJ 2004; 170:1503-18.

8. Patel U, Gandhi G, Friedman S, Niranjan S. Thrombocytopenia in malaria. J Natl Med Assoc 2004; 96:1212-4.

9. Shuaib AH, Khan K, Alauddin A. J Ayub Med Coll Abbottabad 2009;21 (2).

10. Robinson P, Jenney AW, Tachado M, Yung A, Manitta J, Taylor $\mathrm{K}$ et al. Imported malaria treated in Melbourn, Austrlia: Epidemiology and clinical features in 246 patients. J Travel Med 2001; 8:76-81.

11. Rodriguez MAJ, Sanchez E, Vargas M, Piccolo C, Colina R, Arria M. Anaemia and Thrombocytopenia in children with Plasmodium vivax malaria. J Trop Pediatr. 2005; 10:1093.

12. Uddin MM, Uddin JM. Haematological abnormalities in falciparum malaria. BAFMJ. 2007 Dec; XXXIX: 27-31.

13. Imbert P. Criteria of severity in childhood falciparum malaria. Arch Pediatr. 2003;(Suppl 5):532-8.

14. Bashwari LA, Mandil AM, Bahnassy AA, Alshamsi MA, Bukhari HA. Epidemiological profile of malaria in a university hospital in the eastern region of Saudi Arabia. Saudi Med J 2001; 22:133-8.

15. Lathia TB, Joshi R. Can hematological parameters discriminate malaria from non-malarious acute febrile illness in the tropics? Indian J Med Sci 2004; 58:239-44.

16. Mahmood A, Yasir M. Thrombocytopenia: A predictor of Malaria among febrile patients in Liberia. Infect Dis J 2005; 14:41-4.

17. Memon AR, Afsar S. Thrombocytopenia in hospitalized malaria patients. Pak J Med Sci 2006; 22:141-3.

18. Akhtar MN, Jamil S, Amjad SI, Butt AR, Farooq $\mathrm{M}$. Association of malaria with thrombocytopenia. Ann King Edward Med Coll 2005; 11:536-7.

19.Looareesuwan S, Davis JAD. Thrombocytopenia in malaria. South Asian J Trop Med Publ 1993; 23:44-50. 